\title{
O PARADOXO DA INSTITUCIONALIZAÇÃO INFANTIL: PROTEÇÃO OU RISCO?
}

THE PARADOX OF CHILD INSTITUTIONALIZATION: PROTECTION OR RISK?

LA PARADOJA DE LA INSTITUCIONALIZACIÓN DE NIÑOS: ¿PROTECCIÓN O RIESGO?

\author{
Ana Carolina de Oliveira Parra* \\ Jaqueline Alves de Oliveira ${ }^{* *}$ \\ Ana Paula Moraes Maturana**
}

\begin{abstract}
RESUMO
Desde meados do século XX, ganhou destaque o debate acerca dos efeitos da institucionalização de crianças. $\mathrm{O}$ abrigo adquire relação paradoxal entre proteção e risco, podendo ser facilitador ou dificultador para o desenvolvimento de crianças acolhidas. Assim, os objetivos do trabalho foram (1) analisar a produção científica sobre a institucionalização infantil, discutindo os benefícios e efeitos da institucionalização sobre o desenvolvimento de crianças e adolescentes; e (2) compreender como os artigos analisados identificam possíveis fatores de risco e de proteção. Como método, realizou-se uma revisão bibliográfica utilizando os descritores "abrigo"; "institucionalização infantil"; "fatores de risco e fatores de proteção"; "abrigamento prolongado"; "vínculo"; "apego“; "abrigo". Como resultado, 11 trabalhos foram selecionados. As produçôes analisadas apontaram que, embora o abrigo seja um local para acolhimento, assistência e proteção, deve-se estar atento aos fatores de risco e aos impactos negativos da institucionalização. Conclui-se que a institucionalização se faz necessária em alguns casos, devendo ocorrer com qualidade e responsabilidade junto às famílias e com o respaldo de políticas públicas.
\end{abstract}

Palavras-chave: Institucionalização infantil. Abrigo. Risco. Proteção.

\begin{abstract}
Since the mid-twentieth century, the debate about the effects of children institutionalization has been on the spot. The institutional shelter has been getting into a paradoxical relationship between protection and risk and
\end{abstract}

\footnotetext{
Texto recebido em 17 de março de 2016 e aprovado para publicação em 13 de julho de 2016.

*Pós-graduanda na FOP-Unicamp: Especialização em Atendimento Interdisciplinar Preventivo na Primeira Infância, graduada em Psicologia pelas Faculdades Integradas de Jaú (FIJ). E-mail: ana.carolina.parra@hotmail.com.

**Psicóloga com atuação em Políticas Públicas de Saúde, Assistência Social e Educação. E-mail: jakihh_jau@hotmail.com.

***Pós-doutora em Psicologia do Desenvolvimento e Aprendizagem pela Universidade Estadual Paulista Júlio de Mesquita Filho (Unesp/Bauru), doutora em Educação Especial pela Universidade Federal de São Carlos (UFSCar). E-mail: paula.psico@ hotmail.com.
} 
may be understood as either a facilitator or an impediment to children's development. Thus, the objectives of this study are to (1) review scientific literature on child institutionalization, debating the benefits and effects of institutionalization on children's and adolescents' development; (2) understand how the articles analyzed identify possible risk and protection factors. Concerning methodology, we carried out a literature review using the descriptors "shelter"; "child institutionalization"; "risk factors and protective factors"; "prolonged shelter"; "bond"; "attachment"; "shelter". As a result, eleven articles were selected. Result analysis pointed out that although the shelter is a place for refuge, care and protection, one should be aware of the risk factors and the negative impact of institutionalization. It concludes that institutionalization is necessary in some cases, and it should occur with quality and responsibility together with the families and with the support of public policies.

Keywords: Institutionalization child. Risk. Protection.

\section{RESUMEN}

Desde mediados del siglo XX, se hizo destacado el debate sobre los efectos de la institucionalización de los niños. El refugio adquiere una relación paradójica entre la protección y el riesgo, y puede ser un facilitador o un obstáculo para el desarrollo de los niños. Los objetivos del estudio fueron (1) revisar la literatura científica sobre la institucionalización de niños, la discusión de los beneficios y los efectos de la institucionalización en el desarrollo de los niños y adolescentes y (2) entender cómo los artículos analizados identifican posibles factores de riesgo y protección. Como método, se realizó una revisión de la literatura utilizando los descriptores "refugio"; "institucionalización de niños"; "factores de riesgo y factores de protección"; "refugio prolongado"; "vínculo"; "el apego", "la vivienda". Como resultado, fueron seleccionados once artículos. Las producciones analizadas señalaron que si bien el abrigo es un lugar de refugio, cuidado y protección, debe ser consciente de los factores de riesgo y el impacto negativo de la institucionalización. Se concluye que la institucionalización es necesaria en algunos casos, debe ocurrir con la calidad y la responsabilidad de las familias y con el apoyo de políticas públicas.

Palabras clave: Institucionalización de niños. Abrigo. Riesgo. Protección.

\section{INTRODUÇÃO}

$\mathrm{D}$ iariamente, crianças e adolescentes vêm sendo submetidos, em seus próprios lares, a condições que trazem riscos e prejuízos a seu desenvolvimento. Isso inclui todos os tipos de violência doméstica e outros fatores de risco, 
tais como a violência física e psicológica, negligência, abandono, prostituição infantil, falta de higiene e outros, tornando a realidade da infância em nosso país um desafio a ser enfrentado pela sociedade (Maia \& Williams, 2005).

Desde meados do século XX, ganhou destaque o debate acerca dos efeitos da institucionalização precoce de crianças, com ênfase no período da infância. Sabe-se que, nesse período, há possibilidade de manifestações comportamentais e emocionais inadequadas, "sequelas psicológicas" derivadas desse tipo de cuidado infantil. Existe um consenso em torno da ideia de que a institucionalização em si mesma abre um campo favorável para a configuração de várias situações de risco, como privação da convivência familiar, separação da figura de apego, etc. (Cavalcante, Magalhães, \& Pontes, 2007b).

Ainda sobre as consequências da institucionalização, segundo Almeida e Motta (2004 apud Santos et al., 2010, p. 143), quando a pessoa é abandonada, há perdas e lutos a serem elaborados, pois o abandono deixa marcas que se concretizarão na vivência dolorosa de perda e na necessidade de pranteá-las. Além das consequências cognitivas e psicológicas, um estudo feito por Andrade (2011) apresenta os problemas de aprendizagem dessas crianças e adolescentes, e relaciona essas dificuldades devido à insegurança emocional e material fruto da ausência de familiares e de um ambiente estimulador, já que, muitas vezes, nos abrigos, o baixo número de cuidadores por criança pode não favorecer a construção de laços afetivos e significativos de forma a contribuir para futuras dificuldades de aprendizagem.

É na família que a criança deveria encontrar um ambiente propiciador, apoiador, acolhedor e estimulador de suas potencialidades para que, assim, haja um desenvolvimento saudável em aspectos físicos, motores e cognitivos. Durante os primeiros anos de vida, a relação criança e cuidador é marcada pela dependência e é essa relação fundamental para sua constituição como sujeito, seu desenvolvimento afetivo e suas aquisiçōes próprias de cada faixa etária (Bee, 1997). Portanto, espera-se que a institucionalização traga um contexto possível de desenvolvimento e superação dos prejuízos afetivos e intelectuais.

O abrigo, portanto, pode ser facilitador ou dificultador para o desenvolvimento das crianças abrigadas, dependendo da presença ou ausência de fatores de proteção e de risco na entidade, crescendo assim a relação paradoxal entre proteção e risco nos processos de institucionalização de crianças (Salina-Brandão \& Williams, 2009).

Devido às diversas pesquisas e opinióes diferentes em torno da questão, percebeu-se a necessidade de conhecer melhor a realidade da infância e da institucionalização infantil brasileira, conhecida como abrigo. Discutir-se-á 
sobre o histórico da institucionalização infantil no Brasil, que ainda carrega características e paradigmas dos antigos orfanatos e prisões. Considera-se o abrigo como um local de proteção e segurança para a criança, mas que ainda traz consequências e deixa marcas negativas para o desenvolvimento destas.

A hipótese construída neste trabalho é a de que, entre todas as situações negativas vivenciadas por essas crianças, o acolhimento ainda se faz necessário, porém, desde que seja realizado com qualidade, respeitando as individualidades, características e necessidades de cada criança em cada faixa etária, sem esquecer ainda do trabalho realizado juntamente com boas políticas públicas por parte dos governantes, sendo de grande necessidade atender as necessidades das famílias brasileiras, diminuindo a desigualdade social. Assim, os objetivos da pesquisa foram:

a) analisar a produção científica sobre a institucionalização infantil, discutindo os benefícios e efeitos da institucionalização sobre o desenvolvimento de crianças e adolescentes; e

b) compreender como os artigos analisados sobre institucionalização infantil identificam possíveis fatores de risco e de proteção.

\section{MÉTODO}

Afim de alcançar os objetivos propostos, este projeto baseou-se no planejamento de pesquisa de Gil (2002). A pesquisa bibliográfica foi realizada no período de outubro de 2013 a janeiro de 2015, por meio da internet, pelo buscador Google Acadêmico, englobando artigos disponíveis redirecionados para outras bases, como a Scientific Electronic Library Online (Scielo) e Biblioteca Virtual em Saúde (BVS), com os seguintes descritores: "abrigo", "institucionalização infantil", "fatores de risco e fatores de proteção", "abrigamento prolongado", "vínculo, apego e abrigo". Segue a tabela com a quantidade de artigos encontrados e analisados, de acordo com cada palavra-chave: 
Tabela 1 - Trabalhos encontrados de acordo com o descritor ou grupo de descritores

\begin{tabular}{c|c|c|c|c}
\hline Palavras-chave & $\begin{array}{c}\text { Número de } \\
\text { trabalhos } \\
\text { disponíveis }\end{array}$ & $\begin{array}{c}\text { Análise de } \\
\text { títulos }\end{array}$ & $\begin{array}{c}\text { Análise de } \\
\text { resumos }\end{array}$ & $\begin{array}{c}\text { Número de } \\
\text { trabalhos } \\
\text { utilizados }\end{array}$ \\
\hline $\begin{array}{c}\text { Abrigo } \\
\text { Institucionalização infantil }\end{array}$ & 154 & 22 & 9 & 5 \\
$\begin{array}{c}\text { Fatores de risco e fatores de } \\
\text { proteção }\end{array}$ & 279 & 8 & 6 & 1 \\
$\begin{array}{c}\text { Abrigamento prolongado } \\
\text { Vínculo, apego, abrigo }\end{array}$ & 28 & 10 & 7 & 2 \\
\hline Total & 319 & 30 & 9 & 1 \\
\hline
\end{tabular}

Fonte: elaborado pelas autoras.

Com base na revisão sistemática da literatura, foram selecionados 11 trabalhos. Escolheu-se os estudos e pesquisas realizadas nos últimos 15 anos, apenas em páginas em português, com exclusões de citações e patentes. Os artigos foram selecionados considerando o enquadramento com o tema pesquisado e a relevância científica e social. A fim de analisar e problematizar o tema proposto, após a exposição das produções científicas, são apresentadas contextualizações sobre a história do abrigo e acolhimento no Brasil, os motivos da institucionalização e, finalmente, quais são, na visão dos autores, os fatores de risco e de proteção presentes na institucionalização infantil. Atenta-se para o fato de que as discussões após a apresentação dos resultados da revisão de literatura são endossadas por diversos autores da temática proposta.

\section{RESULTADOS DA REVISÃO DE LITERATURA}

Os resultados da revisão de literatura permitiram a localização e posterior análise de 11 produções, sendo 9 artigos científicos e 2 documentos técnicos, que serão discutidos a seguir.

O documento de Orientaçôes Técnicas de Serviços de Acolhimento para Crianças e Adolescentes foi elaborado para regulamentar a organização e ofertas dos serviços de acolhimento para crianças e adolescentes do Brasil, na área da política de Assistência Social (Brasil, 2009). Foram realizadas várias discussões sobre o assunto em fóruns regionais, nacionais e internacionais. Todas as orientaçōes e parâmetros criados têm como objetivo estabelecer orientaçôes metodológicas e diretrizes nacionais para auxiliar que o atendimento no serviço de acolhimento seja provisório, ou seja, transitório, porém reparador. A versão inicial do documento foi elaborada pelo Departamento de Proteção Social Especial Secretaria Nacional de Assistência Social (SNAS) / Ministério da Cidadania(MDS) e, após a análise e aprimoramento do Conselho Nacional de Assistência Social (CNAS) e Conselho 
Nacional dos Direitos da Criança e do Adolescente (Conanda), aberta ao público para consulta em 2008 (Brasil, 2009).

Já o documento sobre o Levantamento Nacional de Abrigo para Crianças e Adolescentes da Rede $S A C$ foi um estudo realizado pelo Instituto de Pesquisa Econômica Aplicada (IPEA) e promovido pela Secretaria Especial dos Direitos Humanos (SEDH) da Presidência da República, por meio da Subsecretaria de Promoção dos Direitos da Criança e do Adolescente (SPDCA) e Conanda. A pesquisa buscou conhecer as características, estrutura de funcionamento e os serviços prestados pelos abrigos beneficiados com recursos do governo federal repassados por meio da Rede de Serviços de Ação Continuada (Rede SAC) do Ministério do Desenvolvimento Social, para que os dados e informaçóes coletados pudessem contribuir para a melhoria das políticas públicas e financiamento dos serviços de abrigo para crianças e adolescentes. A pesquisa foi realizada em 2003. Participaram do estudo 626 instituições de todas as regiōes brasileiras (IPEA, 2003).

Também foi utilizado o artigo e estudo realizado por Salina-Brandão e Williams (2009), que acreditam que profissionais que atuam nos abrigos interferem no desenvolvimento de crianças e adolescentes acolhidos. $\mathrm{O}$ trabalho descreve as estratégias utilizadas pelos profissionais ao avaliarem os abrigos e identificam os indicadores de qualidade que são considerados pelos profissionais quando avaliam as instituições. $\mathrm{O}$ estudo foi realizado em duas etapas, em uma cidade de pequeno porte e em uma cidade de médio porte do Estado de São Paulo, do qual participaram avaliadores e coordenadores dos abrigos. A investigação foi feita mediante entrevistas, análises de relatórios e questionário sobre indicadores de qualidade dos abrigos, sendo analisados segundo o referencial teórico da Psicopatologia do Desenvolvimento, especificamente relacionados aos fatores de risco e proteção (Salina-Brandão \& Williams, 2009).

Pelo artigo e estudo de revisão bibliográfica de Hecht e Silva (2009), foi possível realizar consultas de pesquisas de outros autores não encontrados devido a seus trabalhos serem antigos ou já indisponíveis na internet, sendo de difícil acesso. $\mathrm{O}$ artigo de base psicanalítica relata a importância do vínculo materno no desenvolvimento de crianças, bem como se dá o desenvolvimento psíquico de crianças que vivem em abrigo e não têm o devido vínculo (Hecht $\&$ Silva, 2009).

Também foi utilizado o estudo e pesquisa qualitativa realizada por Orionte e Souza (2007) em um abrigo público estadual, no Município de Goiânia-GO, entre 2002 e 2003. A pesquisa realizada mostra os sentidos e significados que cinco crianças abrigadas, entre 7 e 11 anos, atribuem à sua situação, com a 
finalidade de melhorar as políticas públicas e promover a visibilidade dessas crianças, bem como mostrar a importância do aprimoramento profissional e humano daqueles que atuam diretamente com crianças em abrigo. $\mathrm{O}$ trabalho utiliza-se da abordagem histórico-cultural de Vygotsky e leva em conta que crianças nessa faixa etária já comunicam de forma consciente e pela palavra, suas vivências. A pesquisa foi realizada mediante pesquisa documental com levantamento de informações dos prontuários da instituição participante, além de entrevista semiestruturada e observação (Orionte \& Souza, 2007).

A pesquisa de Nóbrega e Minervino (2011) descreve a importância dos estímulos para aquisição da linguagem, sendo o contexto institucional não favorecedor para isso, pois, para os autores, nesse ambiente, o estímulo é pouco favorecido e o contato das crianças com outros contextos é praticamente nulo. Assim, os autores analisaram o desenvolvimento da linguagem em 32 crianças, entre 0 a 4 anos, de creches e abrigos, sendo os instrumentos utilizados a Escala de Características para Aquisição da Linguagem, elaborada pelas autoras, na qual puderam identificar se as características apresentadas pelas crianças condizem com o esperado para sua idade. Os resultados apresentados afirmam poucas habilidades linguísticas em bebês abrigados comparados com as habilidades daqueles que passam o dia na creche (Nóbrega \& Minervino, 2011).

O estudo de Vectore e Carvalho (2008) compreende a realidade, o universo da criança institucionalizada em abrigo por meio de pesquisa bibliográfica e entrevistas semiestruturadas realizadas com seis funcionários da equipe técnica de uma instituição filantrópica localizada em uma cidade do interior de Minas Gerais. Os resultados apresentados no estudo descrevem os aspectos das concepções de infância da equipe, aspectos da concepção acerca da família de origem e a formação de vínculos no contexto institucional (Vectore \& Carvalho, 2008).

Outro estudo usado foi o realizado pelos autores Cavalcante, Magalhães, e Pontes (2007b), o qual discute aspectos das condições gerais de 287 crianças, de 0 a 6 anos, que foram encaminhadas, acolhidas e cuidadas em um abrigo infantil, considerado o maior do Estado do Pará, entre os anos de 2004 a 2005. O estudo foi realizado mediante consulta a documentos e entrevista semiestruturada com técnicos do abrigo. Os resultados do estudo afirmam que a institucionalização precoce e prolongada de crianças ainda é frequente e que conhecer as condições gerais em que o acolhimento acontece dentro da instituição pode ser um instrumento para possibilitar aos profissionais e autoridades identificar, prevenir e reparar os efeitos desta para o desenvolvimento da criança (Cavalcante, Magalhães, \& Pontes, 2007b). 
O artigo de Cuneo (2009) faz parte do Censo da População Infantojuvenil Abrigada no Estado do Rio de Janeiro e trata sobre os principais efeitos $\mathrm{da}$ institucionalização prolongada de crianças, com enfoque nos aspectos biopsicossociais e relacionados aos vínculos familiares e afetivos. A autora busca afirmar que essa situação impede a ocorrência de condições favoráveis ao desenvolvimento sadio da criança devido à submissão a rotinas rígidas, convívio restrito às mesmas pessoas, da falta de atenção individualizada e o pouco contato com a família e trocas afetivas significativas, entre outros. Segundo Cuneo (2009), a descontinuidade dos vínculos iniciais e a ausência de um referencial cognitivo podem contribuir para uma formação insegura de padróes de apego, podendo levar a prejuízos de ordem somática, intelectual, emocional e social. Assim as marcas que afetam a criança institucionalizada devem ser adequadamente elaboradas, para que a criança não sofra com seus efeitos no futuro.

Já o estudo de Andrade (2011) identifica a qualidade da aprendizagem da escrita em crianças institucionalizadas. Participaram do estudo 20 estudantes da $2^{\mathrm{a}}$ a $4^{\mathrm{a}}$ séries do ensino fundamental de escolas da Rede Pública Estadual de São Paulo, com faixa etária entre 8 e 14 anos, atendidas em abrigo. Os instrumentos utilizados pela autora para a realização da pesquisa foram um questionário de identificação e o teste Avaliação de Dificuldades na Aprendizagem da Escrita (Adape). O resultado da pesquisa afirma que a maioria dos participantes está abaixo da média de acertos e conclui que o contexto e vivência institucionais podem trazer prejuízos cognitivos às crianças acolhidas, principalmente na área da aprendizagem da escrita (Andrade, 2011).

Porfim, oúltimoartigo utilizado, deRotondaro (2002) descreve relatos da autora sobre a construção contínua de formas de trabalhar com crianças e adolescentes que vivem em uma instituição, para proporcionar as mesmas condições para uma boa estruturação pessoal, visando à autonomia e independência. A autora utilizou-se de oito encontros com crianças para avaliação de uma demanda real de terapia, quando foi utilizado o teste de apercepção temática (TAT), e todos os atendimentos tinham a duração de uma hora. Os resultados apresentados pela autora descrevem a falta de conhecimento das pessoas do próprio abrigo em relação ao papel do psicólogo e as dificuldades deste no trabalho dentro do contexto institucional.

\section{CONTEXTUALIZANDO O ABRIGO E A INSTITUCIONALIZAÇÃO INFANTIL}

Os conceitos de família e criança já passaram por várias transformações até chegar ao que conhecemos atualmente. Crianças já foram submissas aos pais, 
chamadas pelos nomes de marginais, pivetes, entre outros olhares e outros termos estigmatizantes. Se retornarmos algum tempo atrás, como o início do século XX, a família tinha como função apenas ensinar valores morais e sociais a seus filhos, cuja metodologia de ensino empregada era, na grande parte das vezes, a agressão física e maus-tratos, em que o abandono era prática comum (Silva, 2012). Nesse contexto, surgiram as primeiras instituições de abrigamento do País. Existentes desde o século XVIII, preocupavam-se mais com as questóes políticas e sociais da época do que com o acolhimento e proteção em si (Silva, 2012; Santos et al., 2010).

\subsection{Das rodas dos expostos aos abrigos atuais}

De acordo com Santos (2013), as primeiras iniciativas de atendimento à criança abandonada no Brasil se deram, seguindo a tradição portuguesa, instalando-se a roda dos expostos nas Santas Casas de Misericórdia, com início ainda no século XVIII. Nesse sistema de recebimento e encaminhamento da roda dos expostos, os bebês abandonados em anonimato eram cuidados pelas amas de leite externas e, depois, aos 7 anos, essas crianças retornavam para a Casa dos Expostos, que procuravam caminhos para colocá-las em casa de famílias ou outras formas para serem criadas (Silva, 2012; Santos et al., 2010; Santos, 2013). As Rodas de Expostos só foram desativadas no ano de 1950, devido aos debates promovidos por médicos higienistas, que se mobilizaram contra a prática (Santos, 2013).

Após a Independência do Brasil, surgiu uma preocupação em amparar a criança órfã e desvalida, apoiada na ideologia cristã, recolhendo essas crianças em instituições mantidas pela Igreja Católica, com subsídio do governo. Essas instituições tinham como características o caráter assistencialista, a impessoalidade, disciplina, rigidez, paternalismo e tinham como objetivo manter a ordem, ou seja, institucionalizar todas aquelas crianças e adolescentes que fugiam dos padrões sociais, que atrapalhavam, de algum modo, a sociedade, excluindo-os da vida social. Em sua maioria, eram crianças e adolescentes pobres, que encontravam nessas instituições a alimentação, vestuário e educação que não teriam em outro lugar (Silva, 2012).

De acordo com Ayres, Coutinho, Sá, e Albernaz (2010), o que havia era uma política de assistência baseada em grandes complexos de internações. A principal característica era a instituição total, ou seja, desde a escolarização até o atendimento de saúde e lazer eram realizados dentro das instituiçôes, baseadas em regras, normas, horários e ocupadas por centenas de crianças; assim, sem respeito à individualidade, características e necessidades de cada criança. As crianças institucionalizadas eram consideradas em situação irregular, ou seja, 
em situação de abandono, em uma circunstância de infração de normas ou até mesmo de pobreza.

De acordo com Silva (2012), foi a partir da década de 1920 que o sistema Judiciário voltou seu olhar para os cuidados com a infância e adolescência. Criou-se o termo "menor de idade", que foi associado à criança e ao adolescente em situação de abandono e marginalidade. É nesse momento que o menor abandonado na rua virou "caso de polícia". Essa nova nomenclatura trouxe um novo estigma e marcou várias crianças e adolescentes que assim foram classificados, pois o termo "menor" implicava a criança carente, impotente, objeto de submissão, preenchimento e, ainda hoje, é usado para desqualificar, generalizar e despersonalizar a criança e o adolescente que vivem na pobreza (Silva, 2012).

Em 1927, surgiu a primeira legislação em relação à criança e ao adolescente do País, o Código dos Menores, de autoria de Mello de Mattos, que tinha como embasamento a doutrina da situação irregular (Silva, 2012; Santos et al., 2010). O Código de 1927 oficializou a intervenção do Estado nas famílias, autorizando-o a vistoriar as casas. Esse período foi marcado pela preocupação social com o aumento dos atos infracionais na adolescência, justificando a criação de uma lógica tutelar para crianças pobres, consideradas delinquentes, mesmo em seu contexto de abandono ou carência econômica (Silva, 2012).

Como não houve a resolução do problema, o Código dos Menores foi revisado, associado ao contexto da Declaração Universal dos Direitos da Criança (1959), tendo por princípio também a prevenção de infrações cometidas por menores. E foi assim que a família passou a ser vista com o papel indispensável no desenvolvimento de seus filhos, seja ela a de origem ou a substituta (Silva, 2012).

A Declaração Universal dos Direitos da Criança (1959), a Declaração Internacional dos Direitos da Criança (1979) e a Convenção Internacional dos Direitos da Criança (1989) trouxeram uma nova compreensão e um novo olhar acerca do mundo infantil e da adolescência, entrando em vigor a doutrina da proteção integral (Silva, 2012). Foi a partir da Constituição Federal de 1988 que se deu início à luta, elaboração e homologação do Estatuto da Criança e do Adolescente (ECA) (Lei no 8.069/1990), em 1990, e, a partir de então, crianças e adolescentes passaram de "objetos de tutela" a "sujeitos de direitos e deveres".

Na história brasileira, diante da situação de pobreza, vulnerabilidade ou risco, a primeira resposta à qual durante muitos anos se recorreu foi o afastamento da criança e do adolescente do convívio familiar, ficando estes, muitas vezes até a maioridade, dentro da instituição, sem qualquer tipo de direito e até mesmo 
liberdade. A promulgação do ECA (1990) veio romper com essa cultura, ao garantir a excepcionalidade da medida, estabelecendo ainda que a situação de pobreza da família não constitui motivo suficiente para o afastamento da criança e do adolescente do convívio familiar. Após o ECA, ficou estabelecido que se devesse recorrer ao encaminhamento da criança e do adolescente ao acolhimento apenas quando esgotados todos os recursos para sua manutenção na família de origem, extensa ou comunidade (Lei no 8.069/1990).

O acolhimento, portanto, é uma medida de proteção prevista no ECA para casos de violação ou ameaça dos direitos das crianças e adolescentes, ou seja, quando os direitos básicos das crianças não são satisfeitos pelos pais, familiares ou responsáveis e também quando o Estado não atua de maneira eficaz mediante políticas públicas e sociais na garantia à proteção social da família, sendo necessário o afastamento (Lei no 8.069/1990).

Segundo a definição do Capítulo III do ECA (Lei no 8.069/1990), o abrigo tem a função de zelar, de proteger a criança e o adolescente por tempo determinado ou indeterminado, reivindicando mediante iniciativas judiciais a volta às famílias de origem ou a destituição de pátrio poder, que culminará em processos de adoção ou inserção em família substituta.

Portanto, de acordo com Orionte e Souza (2007), o acolhimento representa a possibilidade de minimizar a violência, o abandono e sofrimento de famílias, crianças e adolescentes, cujas consequências desses contextos poderiam vir a ser extremamente danosas. Todavia, para realmente se constituir como medida protetiva, o ambiente do abrigo deve ser cuidadosamente organizado, a fim de possibilitar o desenvolvimento adequado da criança e, principalmente, ser um espaço de promoção de vínculos seguros (Vectore \& Carvalho, 2008). De acordo com Arpini (2003), a instituição deve ser um local onde a infância e a adolescência possam ser vividas, onde referenciais identificatórios possam ser construídos, onde seja um espaço verdadeiro de proteção e segurança. No entanto é preciso haver esforços para que haja a transformação dos estigmas que estão presentes nessas instituições, transformar o discurso e a prática institucional para que sejam pensadas como um local onde realmente é possível construir sujeitos, cidadãos.

Os serviços de acolhimento devem, portanto, oferecer um espaço no qual as crianças se sintam protegidas e criem vínculos de confiança; um lugar de acolhimento e socialização que favoreça o desenvolvimento de sua autonomia e criatividade. Para que isso possa acontecer, o projeto da instituição deve ser pautado no olhar individualizado a cada criança ou adolescente, levando sempre em consideração sua história e seu contexto sociocultural (Bernardi, 2010). 
Contudo, mesmo que a criança ou o adolescente esteja em instituições que dão o suporte ideal para seu desenvolvimento saudável, os esforços devem sempre estar voltados para a manutenção do convívio familiar e preservação e fortalecimento dos vínculos e laços familiares, inclusive dos vínculos formados nas instituições, pois esses vínculos são fundamentais para oferecer às crianças e adolescentes condiçôes para um desenvolvimento saudável, tanto fisicamente quanto emocional e psicologicamente, favorecendo a formação de sua identidade e personalidade (Brasil, 2009).

\subsection{Motivos da institucionalização e a criança no abrigo}

De acordo com o Levantamento Nacional de Abrigos para Crianças e Adolescentes da Rede de Serviço de Ação Continuada, realizado pelo (IPEA, 2003), os principais motivos da institucionalização de crianças são: as condições de pobreza, o que descaracteriza o abrigo como lugar temporário; a violência doméstica; o uso de entorpecentes e álcool por pais ou responsáveis; crianças que moram nas ruas; crianças órfãs; cárcere dos pais ou responsáveis; e abuso sexual praticado por familiares. A pobreza é o principal motivo de institucionalização, sendo que de cerca de 20 mil crianças e adolescentes abrigados, 78\% desses têm o abrigo como único lugar de moradia (IPEA, 2003). Dados de pesquisa realizada em 2010 pela Fundação Oswaldo Cruz, a pedido do Ministério do Desenvolvimento Social e Combate à Fome, apontam a existência de 2.624 instituições de abrigo no país para um montante de aproximadamente $37 \mathrm{mil}$ crianças e adolescentes (Assis \& Farias, 2013). Assis e Farias (2013) apontam que atualmente os motivos mais comuns para o abrigamento, em todas as regiōes do país, são a negligência e o abandono. Vale ressaltar que o abrigamento é uma medida de proteção especial provisória e excepcional (Lei no 8.069/1990) dela se valendo "crianças e adolescentes cujos direitos foram desatendidos ou violados, seja por abandono, seja pelo risco pessoal a que foram expostos pela negligência dos responsáveis.

Os principais motivos de afastamento familiar apresentados no texto de Orionte e Souza (2007) foram: carência de recursos materiais da família; abandono pelos pais ou responsáveis; doença dos pais; dependência química do pai, da mãe ou de ambos; prisão dos pais ou responsáveis; abuso sexual; orfandade; mendicância; e violência doméstica.

Segundo Nóbrega e Minervino (2011), a chegada ao abrigo é um momento crucial na vida de uma criança, pois seu universo familiar é substituído pela instituição que a acolhe, seus laços de parentesco, amizades e vizinhança ficam suspensos e ameaçados, assim como sua identidade, pois a definição de quem 
somos envolve, sobretudo, nossa filiação e a comunidade onde nascemos, bem como nossa história. No abrigo, o mundo da criança é alterado e seu futuro indefinido: muitas vezes não sabem de onde vêm, para onde irão, para quem irão e nem em qual condição.

A literatura examinada para realizar o trabalho, além de enfatizar a colocação em abrigo como prática e política social presente na história das sociedades humanas, valoriza a concepção de abrigo como uma instituição que reproduz, ainda hoje, características próprias das instituições totais (prisões, conventos, manicômios, colégios internos, educandários, orfanatos). Dessa forma, a instituição atua oferecendo proteção especial para crianças expostas ao abandono, violência e pobreza, mas também pode acabar expondo inúmeras crianças a outras situações e fatores de riscos e efeitos, como o prejuízo na produção de tarefas e no rendimento escolar, o aumento de atitudes e reaçóes agressivas, malestar, hostilidade, redução de vínculos e afeto entre os sujeitos.

Vail (1966, citado por Aranha, 2001, p. 9) acredita que, no contexto institucional, pode haver a prática de ações irrealistas que, muitas vezes, são inconsistentes com as exigências e características do meio externo. Como consequência, o indivíduo pode se tornar incapaz de administrar e enfrentar o conviver em sociedade. Nesse contexto, faz-se o devido destaque aos trabalhos de Spitz, que realizou estudo pioneiro por meio da observação do comportamento de crianças institucionalizadas no primeiro ano de vida e da aplicação de testes psicológicos (Cavalcante, Magalhães, \& Pontes, 2007a).

Uma das contribuições de Spitz sobre o tema está relacionado à noção de hospitalismo, sendo esse conceito utilizado para designar um conjunto de perturbações vividas por crianças institucionalizadas quando privadas de contato e cuidados maternos (atraso no desenvolvimento, linguagem, adaptação ao meio, entre outros) (Spitz, 1980). Spitz também aponta a presença de uma síndrome que afeta crianças institucionalizadas, chamada de depressão anaclítica, que se caracteriza pela perda gradual de interesse pelo meio, pelo estado de apatia, inapetência e debilidade física na criança institucionalizada. Spitz (1980) explica que a carência pode se dar devido à qualidade dos vínculos, que poderá determinar as consequências oriundas das privações afetivas às quais crianças pequenas são submetidas. Com suas investigações, Spitz confirmou a necessidade de laços e de contatos afetivos entre o bebê e o adulto, especialmente entre a mãe e o filho; a sua ausência pode conduzir a perturbações emocionais, comportamentais e desenvolvimentais graves.

Ao contrário do quese pensa no senso comum, o momento da institucionalização dos filhos é vivido com extremo sofrimento tanto pela criança quanto pela 
família, que sente tristeza e revolta por ter de se afastar dos pequenos, além do medo por saberem que seus filhos podem ser adotados (Silva, 2012). Segundo a mesma autora, outros autores ainda defendem que a institucionalização é sempre uma medida extrema, pois, se a prioridade é que crianças e adolescentes permaneçam em suas famílias, tal como presente no ECA, o acolhimento por si mesmo implica na violação do direito da convivência familiar.

Por isso se faz importante ressaltar o cuidado no uso dessa medida e incentivos para que sejam esgotadas todas as possibilidades de a criança permanecer com sua família, pois tirar uma criança de seu lar, de sua origem pode ser uma medida rápida e mascarar o problema, em vez de resolvê-lo, enquanto seu retorno ao lar nem sempre o é, podendo ainda trazer danos irreparáveis. Devese levar em conta, ainda, que o afastamento familiar pode trazer prejuízos e consequências negativas quanto ao desenvolvimento da criança, principalmente se o atendimento prestado no serviço de acolhimento não for de boa qualidade e prolongar-se sem necessidade (Silva, 2012).

De acordo com Silva (2012), querer tornar-se a família da criança nunca trará para as instituições um lugar legítimo, pois a família da criança, seja qual for, é a família que ela tem, é a sua origem, a qual não pode ser negada ou silenciada, muito menos escondida. Pois, para onde quer que uma criança vá, e até mesmo um adulto, ela leva dentro de si seus sonhos, suas lembranças, sua genética, em seus aspectos bons e maus, a sua família, sua história concreta, vivida, fantasiada e desejada no interior desta. Já para as crianças, as instituições podem constituirse num lugar onde lhe é oferecido afeto, amor, respeito pela primeira vez ou como um lugar que representa o rompimento de seus vínculos, sonhos, família e que, assim, traz sofrimento, medos e angústias (Silva, 2012).

\section{FATORES DE RISCO}

Pode-se dizer que, na maioria dos casos, um ambiente institucional não é um dos melhores ambientes para o desenvolvimento infantil, pois tem como características o atendimento padronizado, número reduzido de cuidadores, falta de preparo e até baixa remuneração dos funcionários, alta rotatividade de funcionários, falta de atividades e estimulação planejadas e a fragilidade das redes de apoio social e afetivo, que colaboram para os prejuízos no desenvolvimento dos indivíduos, ou seja, fatores de risco (Andrade, 2011). Para um melhor e mais adequado tratamento e acolhimento dessas crianças, os cuidados e atenção que recebem nos abrigos devem sempre levar em conta sua faixa etária, suas necessidades individuais e sua história de vida. Entretanto, devido à dinâmica institucional, esses cuidados e atenção não são fornecidos de maneira 
personalizada. São as crianças que precisam se adaptar e se adequar ao padrão de atendimento da instituição (Cuneo, 2009).

Para Nóbrega e Minervino (2011), os danos de um grande período de institucionalização em crianças serão maiores de acordo com a idade destas no momento em que foram afastadas da família, bem como o tempo em que foram privadas do convívio familiar; o tempo de espera que influencia não somente a adaptação da criança em caso de retorno à família de origem, mas também quando acolhida em uma nova família. Assim, quanto mais novas as crianças forem institucionalizadas, maiores as chances de os prejuízos serem irreparáveis, caso o cuidado no contexto institucional não seja de boa qualidade.

Outro problema que crianças que vivem em instituições de acolhimento precisam enfrentar é o preconceito e o estigma social. De acordo com Ayres et al. (2010), conceitos como "menor", "delinquente", "pivete", "abrigado" ou "abandonado" não foram criados por acaso e revelam um posicionamento político e social a respeito da criança pobre, produzindo efeitos na sociedade. Além de tudo o que já foi discutido, percebe-se, na maioria dos estudos, que vários autores concordam quanto ao medo de vinculação que as crianças acolhidas desenvolvem devido a suas experiências negativas de abandono, assim qualquer tipo de vínculo parece ameaçador (Hecht \& Silva, 2009).

\section{FATORES DE PROTEÇÃO}

De acordo com Siqueira e Dell'Aglio (2006), o abrigo é um local de grande importância para a criança, pois é onde ela pode realizar um grande número de atividades, funçôes, interações e um local onde a criança pode desenvolver relações recíprocas de poder, afeto e equilíbrio. Além de moradia, o abrigo é capaz de fornecer recursos para a criança desenvolver a resiliência bem como proporciona recursos para o enfrentamento de todo tipo de situação de vida, positiva, negativa, adversa, felicidade, tristeza, ganhos e perdas. No caso específico da criança institucionalizada, quanto maior for a abertura do abrigo para o ambiente externo, trocas com outras instituições sociais, melhores serão as fronteiras entre os diferentes contextos de desenvolvimento nos quais a criança estará inserida, como a família, creches, escola, igreja, vizinhança e outros (Cavalcante, Magalhães, \& Pontes, 2007a).

Os vínculos estabelecidos dentro das instituições são aliados importantes para ajudar a criança a enfrentar seu passado, presente e futuro. Suas primeiras experiências de vínculo, na maioria das vezes, nem sempre foram positivas, sendo mediadas principalmente por violência de todo tipo e que, muitas vezes, não desaparecem com seu crescimento. De acordo com alguns autores pesquisados 
(Cuneo, 2009; Rotondaro, 2002), pode-se perceber, nos primeiros contatos com as crianças abrigadas, certa desconfiança e medo, mas que, com o tempo, é substituído pelo carinho e uma grande disponibilidade para estabelecer novos vínculos.

É essa afetividade um dos elementos mais importantes para que a criança seja vista novamente. A maneira que o indivíduo percebe o outro depende da forma como o próprio indivíduo foi percebido pelos olhos das outras pessoas, depende das experiências já vivenciadas pelos outros, de acordo com Bee (1997).

Assim, o que pode produzir marcas nas crianças institucionalizadas não é a ausência da mãe, mas a falta de qualquer tipo de relação de afeto e de condições fundamentais para crescer e se desenvolver, e, acima de tudo, a falta de amor, cuidado, carinho, respeito e segurança, falta do apego e do vínculo, é o que trazem as marcas e consequências muitas vezes irreparáveis, seja em qualquer contexto cultural, social, econômico em que o sujeito está inserido (Silva, 2012).

Pode-se afirmar que, comparado ao contexto em que a criança institucionalizada estava inserida, o acolhimento, sem dúvida, traz à criança uma nova oportunidade e uma melhora geral na sua saúde física e psíquica, no seu desenvolvimento cognitivo e psicomotor, além dos cuidados médicos, odontológicos, de higiene, alimentação adequada, acompanhamento escolar, estímulos, tanto para seu desenvolvimento intelectual como afetivo, motor e sensorial, que podem ser considerados um dos vários fatores positivos e de proteção para a criança institucionalizada por um longo tempo (Cuneo, 2009).

Há ainda estudos, pesquisas e autores encontrados durante a realização deste trabalho, como o de Maia e Williams (2005) e de Salina-Brandão e Williams (2009), que acreditam que haja alguns fatores de proteção que possam minimizar os efeitos da institucionalização para o desenvolvimento da criança, seja nos seus primeiros anos de vida ou ao longo de sua vida. Entre outros fatores que vêm sendo investigados, destacam-se: o temperamento, a natureza do vínculo e o padrão de apego com a figura de referência, a idade e o modo como ocorreu a institucionalização, o tempo de permanência no abrigo, a qualidade do cuidado institucional, o ambiente depois da institucionalização e as experiências posteriores na juventude e vida adulta.

\section{DISCUSSÃO}

Talvez as discussões e a relação paradoxal entre risco e proteção nos processos de institucionalização de crianças e adolescentes nunca sejam respondidas ou até nunca terminem, porém é impossível negar a importância das instituiçóes 
de acolhimento, principalmente os abrigos, na vida de tantas crianças e jovens. Ressalta-se que por mais que o abrigo seja um local para acolhimento, assistência e proteção à criança e ao jovem, os trabalhos encontrados, em sua maioria, ainda salientam os fatores de risco e os impactos negativos da institucionalização, bem como déficits, dificuldades, excesso de agressividade, carência de afetos, entre outros, que são algumas das marcas atribuídas à institucionalização.

Após todo o estudo realizado, sabe-se que grandes mudanças ocorreram no processo de institucionalização. Atualmente, as instituições têm instrumentos, capacidade e estão mais bem preparadas para amparar e proteger seus acolhidos. Porém ainda se faz necessário quebrar estigmas e preconceitos existentes em relação aos acolhidos, talvez devido à falta de informação de uma grande maioria da sociedade em relação à realidade institucional e, principalmente, à realidade de tantas crianças e jovens.

Todos os trabalhos encontrados mostram a importância do vínculo com a criança e o adolescente institucionalizados para minimizar os efeitos do afastamento familiar, das vivências muitas vezes traumáticas e também da própria institucionalização. Pelos estudos e artigos pesquisados, pôde-se afirmar que o vínculo (e também a qualidade do serviço oferecido) pode ser o melhor fator de proteção para crianças e jovens institucionalizados. É pelo vínculo que estes poderão construir uma nova visão de si e principalmente do outro, do mundo, das relações, podendo reparar danos e até cicatrizar feridas profundas.

Não se deve deixar de considerar que o mais determinante não é o evento em si (o abandono, privação materna, maus-tratos, negligência), mas a forma como se elabora, lida e enfrenta esse trauma, a forma como o adulto e a até mesmo a criança lidam e dão significado a essa experiência, compreendendo como as outras pessoas vão enxergá-la e auxiliá-la.

\section{CONSIDERAÇÕES FINAIS}

Conclui-se que a institucionalização ainda é importante, desde que seja realizada com qualidade e responsabilidade junto às famílias, com o apoio de políticas públicas sérias e eficazes (que ainda são falhas). A pior marca que pode ficar em uma criança e adolescente não é sua situação como acolhido e nem a institucionalização em si, mas o preconceito, o modo como as pessoas, o mundo as enxergam e as tratam, além das suas próprias vivências e experiências antes do acolhimento e a falta dos pais e da família. É necessário mudar o discurso de menos valia, de despotencialização e de falta que está relacionado à criança institucionalizada. 
O que se pode afirmar é que existe a impossibilidade de chegar a afirmações e verdades absolutas, pois cada instituição tem uma realidade diferente, assim como cada criança tem sua história, sua marca. É necessário que a sociedade compreenda que acolhido não é sinônimo de delinquente, marginal ou falta, mas sim de um ser humano em construção, e cabe a cada um na sociedade o papel e responsabilidade de acolher, de dar oportunidades e um futuro melhor às crianças e adolescentes. 


\section{REFERÊNCIAS}

Andrade, M. S. (2011). Estudo sobre a escrita em crianças e adolescentes abrigados. Revista Psicopedagogia, 28(87). Recuperado a partir de http://www. revistapsicopedagogia.com.br/87/files/revista\%20psicopedagogia\%2087.pdf

Aranha, M. S. F. (2001). Paradigmas da relação da sociedade com as pessoas com deficiência. Revista do Ministério Público do Trabalho, 21, 160-173. Recuperado a partir de http://www.adiron.com.br/arquivos/paradigmas.pdf

Arpini, D. M. (2003). Repensando a perspectiva institucional e a intervenção em abrigos para crianças e adolescentes. Psicologia Ciência e Profissão, 23(1), 70-75. Recuperado a partir de http://pepsic.bvsalud.org/scielo.php?script=sci_ arttext\&pid=S141498932003000100010\&lng=es\&nrm=iso

Assis, S. G. \& Farias, L. O. (2013). Levantamento nacional das crianças e adolescentes em serviços de acolhimento. São Paulo: Hucitec.

Ayres, L. S. M., Coutinho, A. P. C., Sá, D. A., \& Albernaz, T. (2010). Abrigo e abrigados: construçôes e desconstruções de um estigma. Estudos e Pesquisas em Psicologia, Ano10,( 2), 420-433. Recuperado a partir de_http://www.revispsi. uerj.br/v10n2/artigos/pdf/v10n2a09.pdf

Bee, H. (1997). O ciclo vital. Porto Alegre: Artmed.

Bernardi, D. C. F. (Coord.). (2010). Cada caso é um caso: a voz das crianças e dos adolescentes em acolhimento institucional. São Paulo: Associação Fazendo História; NECA (Coleção Abrigos em Movimento, 5). Recuperado a partir de https://www.neca.org.br/wp-content/uploads/Livro5.pdf

Brasil. Secretaria de Direitos Humanos. (2009). Orientaçôes técnicas de serviços de acolhimento para crianças e adolescentes. Brasília: Secretaria de Direitos Humanos. Recuperado a partir de_http://www.sdh.gov.br/assuntos/criancas-eadolescentes/programas/pdf/orientacoes-tecnicas.pdf

Cavalcante, L. I. C., Magalhães, C. M. C., \& Pontes, A. R. (2007a). Abrigo para crianças de 0 a 6 anos: um olhar sobre as diferentes concepções e suas interfaces. Revista Mal-estar e Subjetividade, 7(2), 329-352. Recuperado a partir de http://www.mpsp.mp.br/portal/page/portal/infanciahome_c/acolhimento_ institucional/Doutrina_abrigos/cavalcante_abrigo_para_criancas_de_0_a_6_ anos.pdf

Cavalcante, L. I. C., Magalhães, C. M. C., \& Pontes, A. R. (2007b). 
Institucionalização precoce e prolongada de crianças: discutindo aspectos decisivos para o desenvolvimento. Aletheia, (25), 20-34. Recuperado a partir de http://acolhimentoemrede.org.br/site/wpcontent/uploads/2014/04/ Institucionalizacaooprecoceeprolongadadecriancas.pdf

Cuneo, M. R. (2009). Abrigamento prolongado: os filhos do esquecimento: a institucionalização prolongada de crianças e as marcas que ficam. Rio de Janeiro: Ministério Público do Estado do Rio de Janeiro, MCA. Recuperado a partir de http://mca.mp.rj.gov.br/wp-content/uploads/2012/08/7_Abrigamento.pdf

Gil, A. C. (2002). Como elaborar projetos de pesquisa. São Paulo: Atlas.

Hecht, B. \& Silva, R. F. P. (2009). Crianças institucionalizadas: a construção psíquica a partir da privação do vínculo materno. (Monografia de Conclusão de Curso). Pontifícia Universidade Católica do Rio Grande do Sul, Faculdade de Psicologia, Porto Alegre. Recuperado a partir de http://www.psicologia.pt/ artigos/textos/TL0199.pdf

Instituto de Pesquisa Econômica Aplicada. (2003). Levantamento nacional de abrigos para crianças e adolescentes da Rede SAC. Brasília: IPEA.

Lei no 8.069, de 13 de julho de 1990. (1990, 13 julho). Dispõe sobre o Estatuto da Criança e do Adolescente e dá outras providências. Brasília: Senado federal.

Maia, J. M. D. \& Williams, L. C. de A. (2005). Fatores de risco e fatores de proteção ao desenvolvimento infantil: uma revisão da área. Temas em Psicologia, 13(2), 91-103. Recuperado a partir de http://www.laprev.ufscar.br/ documentos/arquivos/artigos/2005-maia-e-williams.pdf

Nóbrega, J. das N. \& Minervino, C. A. S. M. (2011). Análise do nível de desenvolvimento da linguagem em crianças. Psicologia Argumento, 29(65), 219-226. Recuperado a partir de http://www2.pucpr.br/reol/index.php/ pa?dd99=pdf\&dd $1=4601$

Orionte, I. \& Souza, S. M. G. (2007). Viver em abrigo: com a palavra, a criança. Pesquisas e Práticas Psicossociais, 2(1), 106-129. Recuperado a partir de http:// egov.ufsc.br/portal/sites/default/files/anexos/28422-28433-1-PB.pdf

Rotondaro, D. P. (2002). Os desafios constantes de uma psicóloga no abrigo. Psicologia: Ciência e Profissão, 22(3), 8-13. Recuperado a partir de http://www. scielo.br/scielo.php?pid=S141498932002000300003\&script=sci_arttext

Salina-Brandão, A. \& Williams, L. C. de A. (2009). O abrigo como fator de 
risco ou proteção: avaliação institucional e indicadores de qualidade. Psicologia: Reflexão e Crítica, 22(3), 334-343. Recuperado a partir de http://www.scielo. $\mathrm{br} /$ scielo.php?script=sci_arttext\&pid=S0102-79722009000300003

Santos, A. M. A. dos (2013). Acolhimento institucional de crianças e adolescentes: mudanças na história brasileira. In Anais, 3 Simpósio Brasileiro de Assistentes Sociais, Belo Horizonte. Belo Horizonte: Conselho Regional de Serviço Social de Minas Gerais. Recuperado a partir de http://www.cress-mg.org.br/arquivos/ simposio/acolhimento \%20institucional $\% 20 \mathrm{de} \% 20$ crian $\%$ c3\%87as $\% 20$ e\%20adolescentes $\% 20$ mudan $\%$ c3\%87as\%20na\%20hist $\%$ c3\%93ria\%20 brasileira.pdf

Santos, B. C. A., Ribeiro, M. C. de C., Ukita, G. M., Pereira, M. P., Duarte, W. F. \& Custodio, E. M. (2010). Características emocionais e traços de personalidade em crianças institucionalizadas e não institucionalizadas. Boletim de Psicologia, 60 (133), 139-152. Recuperado a partir de http://pepsic.bvsalud.org/scielo. php?pid=S000659432010000200002\&script=sci_arttext

Silva, M. L. S. (2012). Lei Nacional de Adoção e Acolhimento Institucional: o ponto de vista de psicólogos e assistentes sociais. (Dissertação de Mestrado). Universidade Federal de Santa Maria, Programa de Pós-Graduação em Psicologia da Saúde, Santa Maria.

Siqueira, A. C. \& Dell'Aglio, D. D. (2006). O impacto da institucionalização na infância e na adolescência: uma revisão de literatura. Psicologia \& Sociedade, 18 (1), 71-80.

Spitz, R. A. (1980). O primeiro ano de vida da criança. São Paulo: Martins Fontes.

Vectore, C. \& Carvalho, C. (2008). Um olhar sobre o abrigamento: a importância dos vínculos em contexto de abrigo. Revista Semestral da Associação Brasileira de Psicologia Escolar e Educacional, 12(2), 441-449. Recuperado a partir de http:// www.scielo.br/pdf/pee/v12n2/v12n2a15.pdf 